\title{
Contribuições de John Dewey Na FORMação DE PROFESSORES DE CiÊNCIAS dA NATUREZA
}

\author{
CONTRIBUTIONS OF JOHN DEWEY IN THE TEACHING OF NATURAL \\ SCIENCE TEACHERS
}

DOI: http://dx.doi.org/10.23926/RPD.2526-2149.2020.v5.n1.p412-430.id604

\author{
Mara Elisângela Jappe \\ Goi \\ Doutora em Educação \\ (UFRGS) \\ Professora da Universidade \\ Federal do Pampa \\ (Unipampa) \\ maragoi28@gmail.com
}

Resumo: Este artigo traz os pressupostos teóricos de John Dewey
que foram trabalhados em um curso de formação continuada de
professores da área de Ciências da Natureza em uma universidade
pública. Esses pressupostos podem servir para balizar propostas de
ensino que contemplem o conceito de experiência, a escola e seu
compromisso com a construção de novos saberes a partir da
experiência do indivíduo, da experiência relacionada com os
conceitos científicos, da experiência na escola progressista e das
críticas relacionadas ao campo teórico Deweyano. Assim, na
concepção deste autor a experiência se perpetua naquelas que a
sucedem, logo, uma educação baseada na experiência do indivíduo
será frutífera e criativa nas experiências subsequentes. Desse modo,
o relevante na educação contemporânea é desenvolver a experiência
de vida de cada indivíduo, sendo a escola o lócus para que isso se
desenvolva, priorizando a individualidade de cada um.
Palavras-chave: Palavras-chave: John Dewey; Experiência; formação de professores.

\begin{abstract}
This article presents the theoretical assumptions of John Dewey that were worked on in a continuing education course for professors in the field of Natural Sciences at a public university. These assumptions can serve to guide teaching proposals that include the concept of experience, the school and it is commitment to the construction of new knowledge based on the experience of the individual, the experience related to scientific concepts, the experience in the progressive school and the criticisms related to the Deweyano theoretical field. Thus, in this author's conception, the experience is perpetuated in those that follow it, therefore, an education based on the individual's experience will be fruitful and creative in the subsequent experiences. Thus, what is relevant in contemporary education is to develop the life experience of each individual, with the school being the locus for this to develop, prioritizing the individuality of each one.
\end{abstract}

Keywords: John Dewey; Experience; teacher training. 


\section{INTRODUÇÃO}

Nesta investigação aborda-se os pressupostos teóricos de contribuições John Dewey como referencial apropriado para ser trabalhado em propostas de formação continuada de professores de Ciências da Natureza. Considerando que o professor da Educação Básica não apresenta aprofundamento teórico-metodológico, como já revelou algumas experiências na Educação Básica e na formação de professores, este artigo tem por objetivo trazer alguns pressupostos da teoria do referido autor (GOI, 2004; GOI; SANTOS, 2003, 2005 2009a, 2009b; SANTOS; GOI, 2012; GOI, 2014; GOI, SANTOS; PASSOS, 2014, GOI; SANTOS, 2018)

Assim, neste artigo, propõem-se relatar pressupostos teóricos de John Dewey, da forma em que foi tratado em curso de formação continuada de professores da área de Ciências da Natureza em uma universidade pública do Estado do Rio Grande do Sul. Esta formação foi organizada em três módulos, contabilizando 90 horas de formação, sendo que no primeiro módulo foi tratado os pressupostos teóricos tratados neste artigo.

Os sujeitos dessa experiência foram, na maioria, professores de escolas públicas da Grande Porto Alegre - RS, que lecionam no Ensino Fundamental II, no Ensino Médio e EJA, formados em Ciências da Natureza. Alguns desses sujeitos têm formação em outras áreas do conhecimento, a saber: Bacharel em Química, Engenharia Química, Bacharel em Biologia e Química Industrial. Ao longo da ação de formação o número de professores envolvidos foi se modificando. Por ser um curso ofertado aos sábados e ter uma carga horária de média duração (90 horas), alguns professores desistiram de frequentar o curso devido às demandas profissionais enfrentadas em sua jornada diária, como justificado pelos desistentes. Dos 24 professores matriculados e frequentes até a metade do curso, 18 finalizaram a formação obtendo o mínimo de $75 \%$ de frequência.

Uma parte da ação de formação, foi destinada ao aprofundamento teórico dos referenciais de John Dewey, tratadas neste documento. Este autor se constitui como referencial teórico adequado para trabalhar em programas de formação de professores devido o tratamento adequado ao conceito de experiência, a escola e seu compromisso com a construção de novos saberes a partir da experiência do indivíduo e da experiência relacionada com os conceitos científicos. Assim como, pelos argumentos que utiliza na defesa da tese, de que o ensino pode se constituir levando em consideração a individualidade de cada pessoa. 


\section{Pressupostos teóricos}

\subsection{O CONCEITO DE EXPERIÊNCIA NA VISÃO DE JOHN DEWEY}

Em Dewey (1959), a natureza da experiência pode ser compreendida se for levado em consideração dois elementos antagônicos. Um deles relacionado à experiência como tentativa, e o outro, como sofrimento, ou seja, passar por alguma coisa. A simples atividade não se constitui como experiência, é dispersiva, centrífuga e dissipadora. Nesse modo, a experiência é entendida como mudança quando for refletida, pensada e analisada. A experiência na qualidade de tentativa subentende mudança. Neste contexto a experiência existe quando for concebida como consequência de outra ação.

Para o autor, aprender a experiência seria fazer uma associação retrospectiva e prospectiva entre aquilo que se faz e aquilo que, em consequência, essas coisas fazem gozar ou sofrer. Em tais condições a ação torna-se uma tentativa. Experimenta-se o mundo para saber como ele é e o que sofrer, em consequência, torna-se instrução, isto é, a descoberta das relações entre as coisas.

Diante disso, Dewey (1959) chega a duas conclusões importantes sobre experiência. A primeira está relacionada como uma ação ativa-passiva, não é primeiramente cognitiva; enquanto a segunda está relacionada ao valor de uma experiência em que reside na percepção para a qual ela possa ser conduzida. Para o autor, a experiência seria cognitiva quando for cumulativa ou ao proporcionar alguma coisa significativa.

Assim, pode-se buscar novas alternativas para trabalhar com os alunos e não privilegiar apenas questões cognitivas, que exigem esforço de cada um para manter-se "parado" durante um certo intervalo de tempo. A educação é movimento e o resgate da experiência do indivíduo são novas alternativas articuladas em sala de aula que podem gerar resultado positivo. Deste modo, o indivíduo pode fazer parte desta história, pode ter vez e voz no contexto educacional, a fim de trabalhar com a sua própria experiência.

Dewey (1959) acredita que apesar do indivíduo aprender pela mente (cognição), deve utilizar atividades corporais capazes de instigar os órgãos dos sentidos, como visão, audição, tato, olfato e paladar. Para ele, as atividades corporais são fios condutores por meio dos quais o conhecimento é veiculado do mundo externo para uma compreensão cognitiva.

Outro fator relevante está relacionado às reflexões e incertezas que cada indivíduo faz mediante à experiência. $\mathrm{O}$ ato de pensar contribui para chegar a conclusões, para planejar novas possibilidades e, com isso, gerar muitas incertezas. Para Dewey (1959) a ação de pensar é 
investigação, é pesquisa e pesquisa pessoal, original da pessoa que a faz, é ir por caminhos diferentes que nem sempre serão seguros. Por isso, as reflexões são incertezas e sugerem caminhos a seguir. Desta forma, trilhar os caminhos são tentativas e, fazer tentativas, significa experimentar.

Nessa perspectiva, pode-se constatar que a experiência reflexiva sugere perplexidade, confusão, dúvida, como também, previsão, tentativa de interpretação dos elementos dados, atribuindo-lhes uma possibilidade para produzir certas sequências. Essas experiências reflexivas envolvem a seguinte sequência: i- cuidadoso exame (observação, inspeção, exploração, análise) de todas as considerações possíveis que definam e esclareçam o problema a resolver; ii- elaboração de uma tentativa de hipótese para a experiência reflexiva mais precisa e coerente; iii- tomar como base a hipótese concebida para o plano de ação é fazer alguma coisa para produzir o resultado previsto e, deste modo, pôr à prova a hipótese. As observações, explorações, análises e a elaboração de uma tentativa de hipóteses distinguem uma experiência reflexiva de uma experiência em nível do método de ensaio e erro. Todavia, para Dewey (1959), o indivíduo nunca se livra totalmente das situações de tentativas e erros. Nesse sentido, é necessário trabalhar e valorizar a experiência de cada indivíduo.

Dewey (1959) revela que existem dois princípios fundamentais quando se aborda o contexto da experiência. O princípio da continuidade e o da interação. São considerados aspectos longitudinal e lateral da experiência. Tais aspectos são levados de uma situação para outra. Tudo aquilo que o indivíduo aprendeu torna-se instrumento para compreender e lidar com situações futuras. Este processo continua enquanto a vida e a aprendizagem continuarem. Sendo assim, pode-se dizer que sucessivas experiências integradas entre si possibilitam a construção de um mundo de objetos inter-relacionados. Desse modo, a experiência pode ser vista como crescimento, ela é um continuum, a partir das experiências que são construídas experiências posteriores.

Cabe aqui um desafio, o de desenvolver escolas com base na experiência de vida e requerer uma compreensão da experiência. Uma escola com base na experiência de vida de cada estudante seria na opinião do autor um espaço que prioriza a individualidade de cada um, partindo da sua própria experiência, cujas características são variáveis em cada indivíduo. Nesta concepção, o educador é responsável pelo conhecimento de cada aluno e de matérias que contribuem para a seleção e organização social, em que todos tenham oportunidade de serem atuantes no meio em que estão inseridos. 


\subsection{A ESCOLA E SEU COMPROMISSO COM A CONSTRUÇÃO DE NOVOS SABERES A PARTIR DA EXPERIÊNCIA}

Trabalhar com experiência significa fazer reflexão, mas isso não é trivial, porque é difícil identificar o cenário das experiências de cada indivíduo. Também é difícil descobrir de que forma os conhecimentos construídos através da experiência poderão ser relacionados, conectados e concebidos com os conteúdos escolares.

Nesse sentido, o professor tem um papel fundamental: selecionar os acontecimentos que permitem e estimulem novas formas de observar e julgar, objetivando uma ampliação de futuras experiências. Tudo o que foi trilhado, conquistado, gerado, gestado, permitirá a produção de novas observações priorizando o desenvolvimento cognitivo. Pode-se dizer que o educador que faz a relação entre educação e experiência torna-se responsável pela gradação de tarefas mais sérias e mais difíceis. Ele deve estar atento às potencialidades das experiências para levar os alunos a novos campos e usar o conhecimento dessas potencialidades como critério para seleção e organização das condições que influenciam na experiência de cada um.

Dewey (2010) indica que o ponto mais fraco nas escolas contemporâneas está na seleção e organização das matérias curriculares. Ele afirma que um único plano de estudo para todas as escolas está fora de questão, isso significaria abandonar a vida e as experiências de cada indivíduo, pois o aprendizado deve-se desenvolver a partir de condições de experiências que possam permitir a origem e a busca ativa por informação e novas ideias.

Neste sentido, acredita-se que a escola atual atende algumas das concepções que Dewey aponta como importantes, já que atualmente cada escola tem liberdade de organizar o seu plano de ensino conforme a sua própria realidade. Os conteúdos das matérias de estudo podem ser desenvolvidos progressivamente de acordo com a maturidade e experiência de cada aluno. Portanto, encontrar o material para a aprendizagem dos alunos de acordo com suas experiências é o primeiro passo; o segundo seria apresentar este material de forma mais rica e organizada, aproximando-o do universo de cada indivíduo inserido no contexto escolar.

A possibilidade desta transformação, sem abandonar a conexão orgânica entre a educação e a experiência, seria perceber que a educação acontece fora da escola e independentemente da educação formal. Isso pode ser identificado observando uma criança que aprende a engatinhar, andar e a falar sem estar presente em uma escola. O conhecimento construído por estas experiências requerem novas capacidades, o ambiente, ou seja, o mundo da experiência torna-se maior e o educador, ao perceber tais mudanças, pode buscar novos 
meios de fazer - de forma consciente e intencional - o que a natureza realiza nestes primeiros anos de vida, ou seja, trabalhar com a experiência de vida de cada um.

Dewey (2010) acredita, inclusive, que o princípio da continuidade poder ser mais fácil de ser trabalhado nas séries iniciais, pois, para o professor, não há tanta dificuldade em determinar os tipos de experiências pelas quais as crianças passam ou encontrar atividades que se conectem de forma dinâmica a essas experiências. O autor afirma que seria mais difícil para os professores das séries finais trabalharem com este princípio, pois não é simples identificar o cenário das experiências do indivíduo e descobrir de que forma os conhecimentos construídos através dessas experiências estão relacionados com os conteúdos das matérias utilizadas, com o objetivo de conduzir os alunos em direção às experiências mais organizadas.

Dewey (2010) relata que novas experiências podem estar relacionadas com experiências mais antigas, este é o princípio da continuidade, mas nem sempre, toda e qualquer experiência leva a algo diferente da anterior, por isso, é tarefa do educador selecionar atividades com o potencial de apresentar novos problemas e estimular novas formas de observação e reflexão, ampliando desta forma, a área para experiências futuras.

Assim, o professor pode levar em consideração o que já foi alcançado com o objetivo de abrir novos campos que produzam novas demandas a partir de observações e do uso inteligente da memória. Desse modo, a escola não pode ignorar as experiências passadas, são elas que constituem o meio capaz de possibilitar a compreensão do presente, assim o indivíduo recorre à memória do seu próprio passado para compreender as condições em que ele se encontra, como também, compreender as questões e problemas da vida social.

Dewey (2010) também argumenta que os objetivos corretos do futuro aprendizado estão calcados nas experiências presentes e surtirão efeito à medida em que a experiência esteja fundamentada nas experiências vividas. A compreensão do passado é um meio para compreender o presente, um meio de escapar do sistema escolar que pensa que o passado é um fim em si mesmo, é fazer da compreensão do passado um meio para compreender o presente. Desse modo, enquanto tiver um grupo de pessoas que pense em educação defendendo que o seu único objetivo é a transmissão da herança cultural a outro grupo, que pensa que se deve ignorar o passado e somente pensar no presente e futuro, continuará um embate de ideias e práticas educacionais.

É a partir das experiências dos alunos que os problemas surgem. Na educação progressiva, os problemas são originados a partir de observações constantes por parte dos educadores. Eles originam-se de acordo com a realidade do grupo. Desse modo, Dewey (2010) 
concebe a educação como um espiral contínuo, que conecta o presente e o passado através de suas observações e ações, objetivando a resolução de novas situações. Assim, os problemas não poderão surgir sem a experiência, sem que haja um campo previamente conhecido que apresente novos problemas, instigando a reflexão.

Nesta concepção, o que diferencia uma educação baseada na experiência de uma educação tradicional é o fato de que as condições encontradas a partir das experiências dos estudantes devem ser utilizadas como fontes de problemas. Na educação tradicional isto está fora da competência do aluno, pois o que vale é a simples transmissão de conhecimento. Cabe ao professor conduzir da melhor forma este processo. Em primeiro lugar, o educador pode perceber que os problemas surgem das condições das experiências que estão acontecendo no presente e que sejam coerentes com as habilidades e capacidades dos alunos. Em segundo lugar, o professor deve saber que essas experiências despertam, em cada aluno, a necessidade da busca ativa de informações e de novas ideias.

\subsection{EXPERIÊNCIA RELACIONADA AO CONHECIMENTO CIENTÍFICO}

Dewey (2010) sinaliza que os estudantes devem ser introduzidos ao estudo das Ciências através de seus fatos e de suas leis, como também suas aplicações sociais na vida cotidiana. A inserção desses princípios leva-os a compreender os problemas econômicos, sociais e industriais da sociedade atual. Para o autor, é uma contradição argumentar que processos muito parecidos estudados em laboratório e institutos de pesquisa não façam parte da experiência dos alunos e, muito menos, do escopo da educação baseada na experiência.

É comum não discutir na educação os experimentos elaborados por uma comunidade científica, isto é, experiências de outros e por isso não faz parte do rol de conteúdos apreendidos e estudados pelos alunos da Educação Básica. Segundo Dewey (2010), este fato não exime o educador da responsabilidade de utilizar as experiências apresentadas por uma comunidade científica, desde que sejam conduzidas, gradualmente, através da extração de fatos e leis por elas embasadas. Desse modo, o autor defende que deveriam ser inseridos a discussão e o estudo mais aprofundado de experiências científicas no contexto escolar.

Ainda defende a ideia de que é impossível compreender as forças sociais atuais sem o conhecimento científico, já que, para ele, os métodos científicos também indicam o caminho para medidas e políticas que poderão nos conduzir a uma melhor ordem social, portanto, a escola não deve ignorar o conhecimento científico, pois a sociedade se desenvolveu no último século mediante este conhecimento. O método científico pode se tornar, no contexto 
educacional, um hábito rotineiro. Essa visão seria mais fundamentada se desde as séries iniciais até as finais, esse método fosse visto como o mais importante do sistema educacional, por isso seria estudado com mais rigidez e seriedade (DEWEY, 2010). Assim, o autor usa o método científico como um exemplo de que a Ciência é talvez a melhor demonstração para encaminhar o aluno em um ambiente que tenha condições físicas e humanas refinadas e organizadas comparadas ao que temos no sistema educacional. Para o autor, o ideal seria uma organização progressiva do conhecimento, como se tem no método científico, e atrelada às experiências de vida de cada indivíduo.

A Escola Nova da década de 1930, ao contrário da educação tradicional, privilegia a experiência de cada indivíduo. Esta experiência somente será educativa se considerar a busca de novos conhecimentos, de mais fatos, de mais ideias, tendo um novo arranjo de organização. Dewey (2010) chama isso de organização intelectual, sendo que não é um fim em si mesmo, mas um meio através do qual as relações sociais podem ser mais bem compreendidas e inteligentemente organizadas. Esse fato ele compara ao método científico.

Quando a educação for baseada na experiência do aluno os resultados da aprendizagem poderão ser mais significativos. Dewey (2010), denomina este fenômeno como relação causal porque se encontra de forma consciente na mente da criança. A relação causal não está ausente no sistema educacional, mas os alunos não utilizam as situações e por isso não percebem esta relação. Os estudiosos chamam isto de "análise e síntese" em que os meios são selecionados e organizados em relação a um determinado objetivo. Logo, precisa-se rever os tipos de atividades que a escola vem oportunizando aos estudantes. Para Dewey $(2010$, p.88) [...] "nada pode ser mais absurdo em termos de Educação do que defender a importância de uma variedade de ocupações na escola, menosprezando a necessidade de organização progressiva de informações de ideias." A atividade inteligente presume análise e síntese, pois envolve a seleção de meios dentro de uma variedade de condições existentes (análise) e por seu arranjo e organização a fim de alcançar determinado objetivo ou propósito (síntese).

Conforme o autor, as escolas estão falhando na tarefa de oportunizar ao indivíduo a capacidade de discriminação crítica e habilidade de raciocinar. A habilidade de pensar se dispersa nas informações acumuladas e na tentativa de adquirir diferentes tipos de habilidades que serão usadas no mundo do comércio e negócio, por isso, “alega-se que esses males são resultados da influência científica do pronto atendimento às exigências do presente à custa do sacrifício da inquestionável herança cultural do passado" (DEWEY, 2010, p. 89). 
Dewey vislumbra a ideia de padrões de exploração inteligente da experiência em métodos científicos. Ele sinaliza que, se os educadores retornassem aos métodos e ideias intelectuais que surgiram muito antes do método científico, poderiam ter propósitos mais definidos, mas ele mesmo pensa que seria insensato buscar a salvação nessa direção. A alternativa seria utilizar sistematicamente o método científico como padrão e como ideal de exploração inteligente das potencialidades inerentes às experiências.

Dewey (/2010) deixa claro que não analisa o método científico, mas em qualquer esquema educacional baseado na experiência é preciso considerá-lo. Para ele, o método científico experimental dá mais importância às ideias do que outros métodos, por exemplo, o fato das ideias serem hipóteses e não verdades definidas. As verdades são aceitas e, posteriormente, estudadas, as hipóteses podem ser continuamente testadas e revisadas até serem validadas ou descartadas. É desta maneira que os problemas são resolvidos, o que exigem tentativas e formulações precisas, isto pode ser comparado com o método científico. Ora, a hipótese e a observação encorajam a atividade intelectual, elas levam em consideração as ideias que são testadas pelas consequências que produzem quando aplicadas. $\mathrm{O}$ método científico experimental leva à reflexão, à sumarização em que há tanto discriminação quanto memorização dos aspectos importantes de uma experiência. Ainda mais se esta reflexão oportunizar um olhar para o que aconteceu, extraindo significados que constituem a matéria prima para um comportamento inteligente em futuras experiências, sendo assim, a reflexão constitui-se pela organização intelectual e da mente organizada e disciplinada.

Desse modo, as experiências educacionais levam a um mundo em expansão da matéria de estudo, mas isso somente ocorrerá quando o educador considerar que ensinar e aprender é um processo contínuo de reconstrução da experiência ou quando o educador sentir que as experiências presentes servirão como um movimento que influenciarão as futuras experiências.

\subsection{Críticas À abordagem de DeWey}

As concepções de Dewey promovem mudanças significativas no cenário educacional brasileiro. À medida que as reformas educacionais foram acontecendo, os educadores e profissionais da educação sentiam-se abalados pelas ideias renovadoras e isso, para Cunha (1986), mexeu com o marasmo em que o país se encontrava no século XX.

É preciso destacar que o movimento da Escola Nova trouxe ideias inovadoras, porém, isto não significa que as reformas tenham se mantido com seus objetivos do início ao fim. $\mathrm{O}$ que se viu na prática foi uma distorção ou má interpretação de muitos conceitos trazidos por 
este movimento, como, por exemplo, o fato de muitos professores acabarem fazendo uma interpretação inadequada do processo de ensino, achando que os alunos poderiam aprender por si próprios sem precisar das suas contribuições.

Outro fator que deve ser considerado está relacionado à educação pensada por Dewey, segundo Cunha (1986) exigir recursos pedagógicos imprescindíveis para o desenvolvimento das aulas (produção de material didático, produção de filmes pedagógicos etc.). Na realidade brasileira, parece que esses recursos não foram viabilizados e a proposta de Dewey não foi implementada de forma adequada. Muitos acreditam que a proposta foi desde o início desenvolvida de forma incorreta no país. Para Carvalho (2011), as reformas educacionais acabam ficando confinadas ao mundo das ideias e, muitas vezes, são inviabilizadas ou não concretizadas.

A Escola Nova foi acusada, principalmente, pela "não exigência", por abrir mão dos conteúdos tradicionais e por acreditar ingenuamente na espontaneidade dos alunos. Alguns estudiosos dizem que a Educação Nova não foi um mal em si, ela representou mudanças e avanços frente às práticas pedagógicas, apesar de muitos educadores terem feito uma interpretação inadequada de seus pressupostos. Na verdade, não foi a Educação Nova que não deu certo, mas a sua leitura e interpretação que foram inadequadas (BARBOSA, 2002).

Outra crítica ao movimento da Escola Nova está relacionada ao Modelo de Ensino por Redescoberta, que se configurou no Brasil na década de 1960. A metodologia da Redescoberta, fundamentada na abordagem pedagógica de Dewey, surgiu nos Estados Unidos da América (EUA) visando transformar os estudantes em cientistas. A motivação dos projetos surgiu a partir da corrida espacial entre a antiga União Soviética e os Estados Unidos, tal programa científico foi replicado para diversos países, incluindo o Brasil. Este projeto tinha como objetivo substituir o modelo tradicional de ensino. Na área de Ciências da Natureza se configurou com o nome "projetos de Ensino de Ciências".

No Brasil, esta metodologia foi implementada e adaptada pela FUNBEC (Divisão de Produtos Educacionais da OPTOVAC) e IBECC (Instituto Brasileiro de Educação, Cultura e Ciências) constituindo um eixo inovador na área de Ensino de Ciências. O projeto embasavase nas concepções de Bruner (1966) que considerava que a tarefa de ensinar uma matéria a uma criança, em qualquer idade, é a de representar a estrutura da referida matéria em termos de visualização que a criança tem das coisas (CICILLINI; SICCA,1992). Com isto, objetivava-se a formação de cientistas no contexto escolar. 
O Ensino por Redescoberta caracterizava-se por um conjunto de materiais elaboradas por uma equipe de especialistas que procuraram introduzir um novo currículo e renovar o Ensino de Ciências fazendo uma releitura das obras de John Dewey. A viabilização destes projetos era estabelecida por cursos de treinamento dos professores, que assumiam o papel de aplicadores e a escola assumiria o controle do aluno de acordo com o comportamento que pretende instalar ou manter através de estímulo e reforço. O professor, devidamente "treinado", e com a responsabilidade de planejar e desenvolver o sistema de aprendizagem objetivando maximizar o desempenho do aluno deveria simular o processo científico, controlando a aprendizagem de cada indivíduo que iria redescobrir os conceitos, ou seja, aprender a aprender. O referido ensino buscava formar o cidadão e preparar o trabalhador através da vivência do método científico. O conhecimento alcançado é o resultado direto da experiência e a metodologia é investigativa e experimental, envolvendo atividades com os alunos. Os estudantes "imitam" o trabalho dos cientistas, através de roteiros passo a passo, objetivando alcançar os resultados e conclusões definidos pelo professor. Assim, descobre-se a lógica das ciências, e é nesta perspectiva de refazer passo a passo os experimentos que o Ensino de Ciências é criticado, sabemos que o aluno não consegue desenvolver-se repetindo simplesmente um roteiro de experimentos.

O uso dos processos de investigação científica como metodologia de ensino foi divulgado por uma interpretação dos trabalhos de John Dewey. Na Redescoberta, enquanto método de ensino, há o predomínio de uma visão empirista da Ciência e foi empregada com o objetivo de proporcionar ao aluno a utilização do método científico. Pode-se constatar que esta interpretação foi supostamente errônea. O Ensino por Redescoberta não foi estudado por Dewey, mas foi interpretado por outras pessoas na intenção de confirmar uma metodologia experimental.

O empirismo parte da concepção de que o conhecimento se origina da realidade com os sentidos. Baseia-se na experimentação, validando dados mensuráveis, assim qualquer conhecimento gerado fora da experiência é julgado como suspeito. "Este ideário faz parte de um senso comum disseminado que sustenta a concepção de imitações ingênuas da investigação científica na prática pedagógica, ou seja, que seguindo o "método científico" se obtém resultados análogos aos dos cientistas”. (MARSULO; SILVA, 2005, p.2).

No Ensino por Redescoberta o aluno era concebido como um sujeito que aprende, por isso usava-se o lema "aprender a aprender". O objetivo desta metodologia era proporcionar maior liberdade e autonomia para o aluno aprender e adquirir novos conhecimentos. Naquela 
época, começaram a surgir programas curriculares em nível internacional e estes foram trazidos ao contexto educacional brasileiro sem adaptação à nossa realidade. Esses programas visavam à inclusão de conhecimentos científicos e usavam exaustivamente o laboratório como um local de aprendizagem (KRASILCHIK, 1987).

Para Amaral (1998), o "Método Didático da Redescoberta" alargou-se no cenário educacional brasileiro consideravelmente. Esse movimento objetivava a valorização do método científico e sua transposição para o ambiente escolar, com isso havia um incentivo à participação do aluno e uma consideração efetiva desse método com a formação de um aluno cidadão. $\mathrm{O}$ ensino por Redescoberta no contexto brasileiro foi valorizado de tal maneira que foram criados os Centros de Ciência e na academia observou-se o surgimento de "educadores de Ciências" como uma nova comunidade acadêmica. Devido a isso, a pesquisa no Ensino de Ciências aumentou e iniciou-se a constituição de uma área de Ensino de Ciências.

O Ensino pelo Método da Redescoberta, no Brasil, começa a perder força na década de 80. Nesse momento, as críticas em relação a esta proposta começam a vir à tona. Amaral (1998), argumenta que isso aconteceu devido à emergência de novas ideias e à necessidade de incorporação de uma proposta que privilegiasse o cotidiano dos alunos. O crescente reconhecimento da importância da aprendizagem a partir dos conhecimentos prévios dos alunos começa a ser estudado, bem como a noção de interdisciplinaridade começa a ganhar destaque no campo educacional. Tudo isso gera uma nova reflexão sobre a maneira do aluno aprender e quais as melhores maneiras da incorporação desta aprendizagem.

A Redescoberta foi alvo de muitas críticas entre os pesquisadores do Ensino de Ciências. Hodson (1985), após realizar um levantamento sobre as concepções do método científico, concluiu que não há um acordo entre os filósofos da Ciência em torno do método, devido, talvez, à complexidade da própria ciência, o que dificulta sua caracterização e aplicação de ensino.

Na área de Ciências da Natureza, todos os debates e críticas voltadas ao ensino citado aconteceram devido a outros movimentos e metodologias trabalhados no campo educacional a partir de 1980. Um exemplo que marca fortemente esta ideia é o debate que ocorreu sobre as diversas formas de ensinar e aprender relativos ao Movimento das Concepções Alternativas (MCA) e o movimento construtivista do Ensino de Ciências que viabilizaram a investigação de propostas que possibilitassem um ensino mais significativo. 


\subsection{DeWey E a Escola Nova no Brasil: aspectos CRUCIAIS NA FORMAÇÃo de PROFESSORES}

O debate sobre formação docente há anos vem se aprimorando. A literatura educacional vem tratando da formação profissional com diferentes objetivos. Desde meados da década de 1920, a economia, política e a sociedade debatem sobre os problemas relacionados à educação. Para Brzezinsk (1996), a educação do século XX passou a ser vista com outros olhos, como reconstrução social e a ela foi atribuído o desafio de trabalhar com as novas condições de vida e com o desenvolvimento urbano da época.

Para Júnior e Donatoni (2006) o Decreto nº 19.851 de 1931 foi um marco importante para a formação de professores ao estabelecer o Estatuto das Universidades Brasileiras. Esse documento foi elaborado por Francisco Campos e pressupunha a inovação das Faculdades de Letras, Ciências e Educação, com o objetivo, destas poderem substituir uma das escolas tradicionais da época, Medicina, Engenharia e Direito. Para Evangelista (1997), essa época foi produtiva à medida em que as universidades estavam discutindo e sugerindo à preparação do magistério. O ministro Francisco Campos previa a autonomia das universidades e a criação de instituições dedicadas à pesquisa. Entretanto, isso estava muito afastado da nossa realidade e não se concretizou, bem como não houve progresso para a efetiva consolidação da Faculdade de Educação Letras e Ciências, prevista em lei no ano de 1931 (JÚNIOR; DONATONI, 2006).

Ainda em Júnior e Donatoni (2006), apesar da reforma universitária de 1931 ter previsto uma abrangência nacional para a Faculdade de Educação, a institucionalização da formação superior do professor ficou restrita aos Estados de São Paulo e Rio de Janeiro. A conquista de um espaço acadêmico para os debates em torno da formação superior do professor ganhou impulso pelo movimento renovador que pregava a profissionalização das atividades dos educadores. Além de criar maior visibilidade às críticas dirigidas às escolas normais, o movimento da Escola Nova, se empenhou em oferecer um novo modelo que corrigisse as insuficiências e distorções do modelo humanista tradicional vigente. Todo esse avanço foi bastante influenciado pelos ideais escolanovistas.

Fernando de Azevedo e Anísio Teixeira, promotores do movimento da Escola Nova no Brasil, consolidaram uma nova consciência educacional, relativa à função do Estado na educação, objetivando a expansão da escola pública, do direito de todos à educação e da necessidade da implementação de uma política pública nacional para o ensino. O movimento da Escola Nova marcado pelas concepções de John Dewey centrava-se na revisão dos padrões tradicionais de ensino, sendo estes não mais programas rígidos, mas flexíveis, adaptados ao 
desenvolvimento e à individualidade das crianças. A educação do século XX era centrada como resultado das experiências e atividade dos alunos, sob o acompanhamento do professor e do ensino ativo em oposição a um ensino tradicional (TANURI, 2000).

O "Manifesto dos Pioneiros" do século XX com vertente nas concepções de John Dewey teve repercussão nacional, porém esse movimento foi intenso na formação de professores secundários e nos projetos acadêmicos de São Paulo, Rio de Janeiro e Distrito Federal. O Estado de São Paulo assumiu os estudos pedagógicos de nível público superior, com o objetivo de formar professores. Em 1920, Sampaio Dória propunha uma reformulação da faculdade de Educação, esta não se concretizou, mas, influenciou a criação de um curso de aperfeiçoamento na Escola Normal da capital, transformada em Instituto Pedagógico por Lourenço Filho em 1931.

Na década de 30, Fernando de Azevedo, como Diretor Geral da Instrução Pública do Estado de São Paulo, criou o Instituto de Educação, antigo Instituto Pedagógico, pelo Decreto $\mathrm{n}^{\circ}$ 5.846, considerado como a primeira escola em nível superior que enfatizava a formação de professores. O então diretor acreditava no preparo docente como espírito de renovação das concepções pedagógicas, ele não era contra as escolas normais para formação docente, mas, acreditava que o preparo dos mestres deveria ser realizado em um Instituto Superior, por isso a criação desta instituição em 1933, como resultado de sua reforma educacional no Estado de São Paulo (EVANGELISTA, 2001).

A formação de professores secundários em nível superior se iniciou com a incorporação do Instituto de Educação ao decreto da criação da Universidade de São Paulo em 1934. Através desta reforma, o Instituto de Educação passou de escola superior à Universidade como Faculdade de Educação (BRZEZINSKI, 1996). Esse instituto assumiu a produção de pesquisa, o preparo de professores primários e secundários e administradores escolares, no entanto, a formação de professores tinha o status universitário referendado pela Faculdade de Filosofia, Ciências e Letras da USP.

Segundo Júnior e Donatoni (2006), a formação de professores foi conduzida de forma que os conhecimentos viabilizassem aos professores uma maior aproximação à realidade social e escolar dos seus alunos. A criação dos centros de educação causou um deslocamento dos "conteúdos" que as escolas estavam habituadas a ensinar para a execução de métodos e processos de ensino, valorizando as "Ciências da Educação" que abrangiam a Biologia e a Psicologia. 
Fernando de Azevedo era diretor do Instituto de Educação da Universidade de São Paulo (IEUSP) e almejava um ensino de caráter experimental, para ele, os laboratórios eram fundamentais na "vida do instituto". Houve, então, um abandono ao recorte propedêutico e retórico da formação tradicional e uma nova concepção de formação técnica e profissional do professor. Não se tratava apenas de saber o que ensinar, mas de saber como ensinar. Dessa forma a Psicologia, ao lado da Biologia e da Sociologia, auxiliaram nesse novo processo (JÚNIOR; DONADONI, 2006).

Fernando de Azevedo (1971) relata que, em 1937, houve a diplomação da primeira turma de professores do Brasil, pela Universidade de São Paulo. Entretanto, como ele afirma, apesar de ser uma das respostas à demanda por qualificação profissional, o IEUSP teve sua continuidade encerrada pelo decreto estadual no 9.268 A, de 25 junho de 1938, devido às forças políticas ligadas ao Estado Novo e à Igreja Católica (JÚNIOR; DONATONI, 2006).

Anísio Teixeira fez contribuições significativas no cenário educacional brasileiro em relação à formação de professores. Em 1932, ele transformou a Escola Normal do Distrito Federal em Instituto de Educação como "entidade modelar" para a formação de professores. Também como Fernando de Azevedo em São Paulo, Anísio Teixeira, durante sua administração pública no Distrito Federal, foi duramente criticado pela Igreja Católica, que o acusou de comunista e materialista, mesmo assim continuou mantendo seu ideal de Educação.

A Igreja Católica e o ministro Gustavo Capanema, demonstravam-se contra a referida proposta da criação de uma universidade, mas, Getúlio Vargas, por motivo político, autorizou o decreto da criação da instituição, mesmo passando por cima das concepções do Ministro da Educação. Em 1935, foi assinado pelo prefeito Pedro Ernesto o Decreto 5.513, que instituía a Universidade do Distrito Federal, que dentre várias finalidades, previa a formação do magistério em todos os seus graus. A Universidade do Distrito Federal apresentava três faculdades tradicionais, entre as quais situava-se o Instituto de Educação, chamado Faculdade de Educação, por priorizar aspectos da formação de professores.

Anísio Teixeira, como estudioso da teoria de Dewey, concedia ao professor primário e secundário a reconstrução da sociedade, almejava a formação de professores e transmitia aos futuros profissionais da Educação uma sólida cultura geral, firmeza e profundidade na disciplina de conteúdo específico e dava grande destaque à formação pedagógica. Apesar dessas atribuições inovadoras para a formação de professores, com um padrão renovador, a situação política durante a década de 35 não era nada promissora. Após a Intentona Comunista de novembro, os caminhos para o Estado Novo e uma ação centralizadora mexeram com os novos 
rumos que a Educação estava tomando. A Universidade do Distrito Federal foi fechada em 1939 e os motivos do fechamento podem ser atrelados à perseguição política dos católicos que não aprovaram o projeto educacional renovador de Teixeira.

Assim, aponta-se que as concepções de Dewey marcaram o cenário de lutas nas reformas educacionais brasileiras, bem como vários estudiosos trouxeram os seus referenciais para a inovação da formação de professores. Esses aspectos são relevantes e podem ser tratados atualmente em curso de formação docente, pois possibilitam ao professor uma visão das reformas de ensino para compreender as questões contemporâneas da educação.

\section{CONSIDERAÇÕES FINAIS}

Um elemento tratado por Dewey (1959), que para ele é fundamental, está relacionado ao conceito de experiência. Para o autor, experiência é passar por alguma coisa que tenha significado pessoal, que deve ser refletida, pensada e analisada. Assim, a experiência está relacionada a mudanças.

Tanto o movimento da Escola Nova quanto a educação tradicional propõem inúmeras experiências. Todas as experiências ocorrem diariamente no contexto escolar, assim, é relevante refletir sobre a importância das experiências e promover mudanças no contexto educacional. Nessa perspectiva, toda a experiência vive e se perpetua nas experiências que a sucedem, logo, uma educação baseada na experiência deverá ser mais relevante e criativa nas próximas experiências.

Desse modo, o processo educativo pode ser identificado como crescimento, como desenvolvimento físico, intelectual, moral e ético. Mas o crescimento não é suficiente, deve-se especificar a sua direção e a sua tendência final. Assim, o professor deve apresentar direção e sentido no processo de ensinar e aprender, ou seja, sua tarefa é ver em que direção caminha uma experiência e avaliar quais atitudes realmente conduzem ao crescimento e quais delas são prejudiciais.

O relevante na educação contemporânea é desenvolver a experiência de vida de cada indivíduo. Uma escola com base na experiência de vida de cada estudante é, na opinião de Dewey (2010), um espaço que prioriza a individualidade de cada um, partindo da sua própria experiência, cujas características são variáveis em cada indivíduo.

Pensar em uma proposta nesta dimensão, na visão de Dewey seria formar o professor que possa selecionar os acontecimentos que permitem e estimulem novas experiências de vida 
e novas formas de observar e julgar, com a proposição de ampliar as experiências de cada indivíduo.

Nesta perspectiva, fazer um aprofundamento teórico na formação de professores sobre as concepções de Dewey fortalece os saberes práticos e a pesquisa reflexiva, ao mesmo tempo em que torna visíveis as dificuldades conceituais enfrentadas por esses profissionais em relação ao conhecimento de sua disciplina. Soma-se a isso o fato de permitir uma estrutura que possibilita ao professor formar-se continuamente por meio da mobilização de suas próprias experiências.

\section{REFERÊNCIAS}

ALVES, Marcelo Lima. A política de capacitação SEE/FDE. Cadernos Cedes, Campinas, $\mathrm{N}^{\circ}$ 36, p. 57-64, 1995.

AMARAL, Ivan. Amorosino. Currículo de Ciências: tendências clássicas aos movimentos atuais de renovação. In: BARRETO, Elba. S. S. Os Currículos do Ensino Fundamental para as escolas brasileiras. Campinas: Autores Associados, São Paulo: Fundação Carlos Chagas, p. 201-232, 1998.

AZEVEDO, Fernando. A Cultura Brasileira. 5a . ed. São Paulo: Melhoramentos Edusp, 1971a.

BARBOSA, Ana Mãe. John dewey e o Ensino da Arte no Brasil. $5^{\text {a }}$. ed. São Paulo: Cortez, 2002.

BREZEZINSKI, Iria. Pedagogia, pedagogos e formação de professores. Campinas: Papirus, 1996.

CARVALHO, Janete Magalhães; SIMÕES, Regina Helena da Silva. O processo de formação continuada de professores: uma construção estratégico-conceitual expressa nos periódicos brasileiros.Caderno de Pesquisa, V 1, p. N 1, 11-39, 1999.

CARVALHO, Viviane Batista. As influências do pensamento de John Dewey no cenário educacional brasileiro. Revista Redescrições- Revista online do GT de Pragmatismo, Ano 3, Número 1, 2011.

CICILLINI, Graça Aparecida; SICCA, Natalina Aparecida. Laguna. O Ensino de Ciências: Metodologias de Ensino e Método Científico. Ensino em Revista, Uberlândia, V. 1, N 1, p. 37-41, 1992.

CUNHA, Fátima. Filosofia da Escola Nova:do ato político ao ato pedagógico. Rio de Janeiro: EDUFF, 1986.

DEWEY, John. Democracia e Educação. Trad. Godofredo Rangel,; Anísio Teixeira. São Paulo: Nacional, 1959. 
DEWEY, John.Experiência e Educação. Tradução de Renata Gaspar-Petrópolis, RJ: Vozes. Petrópolis, RJ: Vozes, 2010.

EVANGELISTA, Olinda. A Formação do professor em nível universitário: O Instituto de Educação da Universidade de São Paulo (1934 - 1938). Tese (Doutorado em Educação) PUC, São Paulo,1997.

EVANGELISTA, Olinda. Formar o Mestre na Universidade: A Experiência Paulista nos Anos de 1930. Disponível em: htpp://www.scielo.br/scielo.php?script=script_arttext.Acesso em 28 setembro 2012. Edu.Pesq,V27, N 2, 2001.

GOI, Mara Elisângela Jappe. A Construção do conhecimento químico por estratégias de Resolução de Problemas. Canoas: ULBRA, 151, 2004.Dissertação de Mestrado. Programa de Pós-graduação em Ensino de Ciências e Matemática, Universidade Luterana do Brasil, ULBRA.

GOI, Mara Elisângela Jappe; SANTOS, Flávia Maria Teixeira. A Construção do Conhecimento Químico por Estratégias de Resolução de Problemas. IN: IV Encontro Nacional de Pesquisa em Educação em Ciências, Bauru. Atas do IV Encontro Nacional de Pesquisa em Educação em Ciências, Porto Alegre: Universidade Federal do Rio Grande do sul, único, 1-12, 2003.

GOI, Mara Elisângela Jappe; SANTOS, Flávia Maria Teixeira. Construção do conhecimento químico por estratégias de Resolução de Problemas. In: Encontro de Debates de Ensino de Química (Minicurso). Ijuí, 2005.

GOI, Mara Elisângela Jappe; SANTOS, Flávia Maria Teixeira. Reações de Combustão e Impacto Ambiental por meio de Resolução de Problemas e Atividades Experimentais.

Química Nova na Escola, V. 31, p. 203-209, 2009a.

GOI, Mara Elisângela Jappe; SANTOS, Flávia MariaTeixeira. Resolução de Problemas e Atividades Experimentais nas Aulas de Química: Relato de Experiências, 2009, Lajeado. In: Anais do IX Encontro sobre Investigação na Escola. Lajeado. Univates, p. 1-5, 2009b.

GOI, Mara Elisângela Jappe; SANTOS, Flávia Maria. Teixeira; PASSOS, Camila Greff. Formação Continuada de Professores de Ciências: uso da metodologia de resolução de problemas. In: 2D International Congress of Science Education. Foz do Iguaçu, PR. Proceedings of the 2d International Congress of Science Education. Foz do Iguaçu, PR: UNILA. v. 1. p. 1-1., 2014.

GOI, Mara Elisângela Jappe. Formação de professores para o desenvolvimento da metodologia de resolução de problemas na Educação Básica. Tese de Doutorado. Porto Alegre: PPGEDU/UFRGS, 2014.

HODSON, Derek. Philosophy of Science, Science and Science Education.Studies in Science Education, V. 12, 1985.

JÚNIOR, Alberto da Cunha Bragato; DONATONI, Alaíde Rita. A institucionalização da formação universitária de professores secundários da década de 1930. RPD-Revista Profissão Docente, Uberaba, V.6, N. 14, p. 23-40, 2006. 
KRASILCHIK, Myriam. O professor e o currículo de ciências no $\mathbf{1}^{\mathbf{0}}$ grau. São Paulo: Atual, 1987.80 p.

MARSULO, Marly Aparecida. Giraldeli; SILVA, Rejane Maria Ghisolfi.Os métodos científicos como possibilidade de construção de conhecimentos no ensino de ciências. Revista Electrónica de Enseñanza de las Ciencias Vol. 4, № 3.Revista Electrónica de Enseñanza de las Ciencias, V. 4, N 3, 2005.

SANTOS, Flávia Maria Teixeira; GOI, Mara Elisângela Jappe. Resolução de Problemas no Ensino de Química fundamentos epistemológicos para o emprego da metodologia na Educação Básica. In: Anais do XVI Encontro Nacional de Ensino de Química / X Encontro de Educação Química da Bahia. Salvador: Editora da Universidade Federal da Bahia, p. 1-11, 2012.

TANURI, Leonor Maria. História da Formação de Professores. Revista Brasileira de educação, São Paulo, Nº 014, p. 61-88, 2000.

Recebido em: 11 de janeiro de 2020.

Aprovado em: 25 de abril de 2020. 